Further Section

Brain Behav Evol 1985;27:217

\title{
Author Index Vol 27, 1985
}

Bass,A.H. 115 Braford, M.R., Jr. 80 Cotton, P. 41 Cruce, W.L.R. 106, 195 DiDomenico, R. 132 Duvall, D. 186 Eaton, R.C. 132 Fite, K.V. 48 
Graves, B.M. 186 Griisser-Cornehls, U. 165 Hayden, D. 48 Hofman, M.A. 28 Karten, H.J. II Langeveld, S. 165 Mackay-Sim, A. 186 Manteuffel, G. 1 
Montgomery, J.C. 41 Reiner. A. 1 I Rosenthal, B.M. 106. 195 Saidel, W.M. 80 Schwerdtfeger, W.K. 93 Shambes, G.M. 57 Welker, W. 57 